Check for updates

Cite this: Phys. Chem. Chem. Phys., 2020, 22, 16345

Received 31st January 2020,

Accepted 18th June 2020

DOI: $10.1039 / \mathrm{d} 0 \mathrm{cp} 00538 \mathrm{j}$

rsc.li/pccp

\title{
Ion chemistry of phthalates in selected ion flow tube mass spectrometry: isomeric effects and secondary reactions with water vapour $\dagger$
}

\author{
Michal Lacko, (D)*ab Bartosz Michalczuk, (D) c Štefan Matejčik (D) ${ }^{c}$ and \\ Patrik Španěl (iD ${ }^{\text {a }}$
}

\begin{abstract}
Phthalates are widely industrially used and their toxicity is of serious environmental and public health concern. Chemical ionization $(\mathrm{Cl})$ analytical techniques offer the potential to detect and monitor traces of phthalate vapours in air or sample headspace in real time. Promising techniques include selected ion flow tube mass spectrometry (SIFT-MS), proton transfer reaction mass spectrometry (PTR-MS) and ion mobility spectrometry (IMS). To facilitate such analyses, reactions of $\mathrm{H}_{3} \mathrm{O}^{+}, \mathrm{O}_{2}{ }^{+}$and $\mathrm{NO}^{+}$reagent ions with phthalate molecules need to be understood. Thus, the ion chemistry of dimethyl phthalate isomers (dimethyl phthalate, DMP - ortho; dimethyl isophthalate, DMIP - meta; dimethyl terephthalate, DMTP para), diethyl phthalate (DEP), dipropyl phthalate (DPP) and dibutyl phthalate (DBP) was studied by SIFT-MS. Reactions of $\mathrm{H}_{3} \mathrm{O}^{+}, \mathrm{O}_{2}{ }^{+}$and $\mathrm{NO}^{+}$with these phthalate molecules $\mathrm{M}$ were found to produce the characteristic primary ion products $\mathrm{MH}^{+}, \mathrm{M}^{+}$and $\mathrm{MNO}^{+}$, respectively. In addition, a dissociation process forming the $(\mathrm{M}-\mathrm{OR})^{+}$fragment was observed. For phthalates with longer alkyl chains, mainly DPP and DBP, a secondary dissociation channel triggered by the McLafferty rearrangement was also observed. However, this is dominant only for the more energetic $\mathrm{O}_{2}{ }^{+}$reactions with phthalates, additionally resulting in a recognisable formation of the protonated phthalate anhydride. For the $\mathrm{NO}^{+}$reagent ions, the McLafferty rearrangement makes only a minor contribution and for $\mathrm{H}_{3} \mathrm{O}^{+}$, it was not observed. Experiments on the effect of water vapour on this ion chemistry have shown that protonated DMIP and DMTP efficiently associate with $\mathrm{H}_{2} \mathrm{O}$ forming the DMIP. $\mathrm{H}^{+} \mathrm{H}_{2} \mathrm{O}$, DMIP. $\mathrm{H}^{+}\left(\mathrm{H}_{2} \mathrm{O}\right)_{2}$ and DMTP. $\mathrm{H}^{+} \mathrm{H}_{2} \mathrm{O}$ cluster ions, whilst the protonated ortho DMP isomer as well as other ortho phthalates DEP, DPP and DBP does not associate with $\mathrm{H}_{2} \mathrm{O}$. The results indicate that the degree of hydration can be used to identify specific phthalate isomers in $\mathrm{Cl}$.
\end{abstract}

\section{Introduction}

Phthalates (esters of phthalic acid) are used in the production of plastics as plasticizers and their environmental and health impacts are now well understood. Phthalates are characterized as endocrine disruptors that represent a major hazard for pregnant women and children under 3 years. ${ }^{1,2}$ Several of the most dangerous phthalates (diethylhexyl phthalate, dibutyl phthalate, benzylbutyl phthalate, diisononyl phthalate, diisodecyl phthalate, and di- $n$-octyl phthalate) are regulated by EU regulations $^{3}$ or tracked by the European Chemical Agency. ${ }^{4}$

${ }^{a} J$. Heyrovsky Institute of Physical Chemistry of the CAS, v. v. i. Dolejškova 2155/3, 18223 Prague, Czech Republic. E-mail: patrik.spanel@jh-inst@cas.cz

${ }^{b}$ Charles University, Faculty of Mathematics and Physics, V Holešovičkách 747/2, 180 oo Prague, Czech Republic

${ }^{c}$ Comenius University in Bratislava, Faculty of Mathematics, Physics and Informatics, Mlynska dolina, 84248 Bratislava, Slovakia

$\dagger$ Electronic supplementary information (ESI) available. See DOI: 10.1039/ d0cp00538j
However, these regulations only cover toys and are not concerned with other daily products. Phthalates can thus be present in plastic containers, ${ }^{5}$ cosmetics $^{6}$ and toothbrushes. ${ }^{7}$ Phthalates were additionally detected in indoor air and dust ${ }^{8}$ or in seawater. ${ }^{9}$ Further risk of exposure to phthalates may also arise from the import of products from countries without regulations in place.

Several analytical techniques are used for the detection of phthalates, mainly based on gas chromatography - mass spectrometry using electron ionization, EI, at $70 \mathrm{eV} .^{10,11}$ The notable feature observed in phthalate mass spectra is a common fragment ion of the protonated phthalate anhydride with the mass to charge ratio $m / z 149$. This mass peak is characteristic for most phthalates with longer alkyl substituents. Whilst the appearance of the $m / z 149$ peak is a good indicator for the presence of phthalate, the selectivity between the different phthalate compounds by EI is limited. Chemical ionization (CI) combined with liquid chromatography has been shown to provide better selectivity between different phthalates. ${ }^{12}$ 
The aim of the present study is to investigate the possibilities of analyzing phthalate vapours via proton transfer reaction mass spectrometry (PTR-MS) and selected ion flow tube mass spectrometry (SIFT-MS). These techniques are mainly used in the real time detection of VOCs present at trace levels ${ }^{13}$ and were successfully applied in several analytical applications including breath research, food flavour analysis, environmental monitoring and homeland security. ${ }^{14-16}$ It is, therefore, important to understand the ion chemistry of phthalates related to SIFT-MS and PTR-MS not only to facilitate their analyses, but also to gain insight into the reaction mechanism by observing trends in changes of reactivity with the phthalate molecule size and structure. Recently, atmospheric pressure chemical ionization (APCI) and ion mobility spectrometry (IMS) were combined to study dimethyl phthalate isomers showing interesting selective behaviour in the formation of protonated phthalate water clusters where the ortho orientation of phthalate esters does not form water clusters whilst the other two conformers do. ${ }^{17}$

In the present study, we have investigated the $\mathrm{H}_{3} \mathrm{O}^{+}, \mathrm{NO}^{+}$ and $\mathrm{O}_{2}{ }^{+}$ion reactions with dimethyl phthalate (DMP), dimethyl iso-phthalate (DMIP), dimethyl terephthalate (DMTP), diethyl phthalate (DEP), dipropyl phthalate (DPP) and dibutyl phthalate (DBP) via SIFT-MS. Secondary reactions of the protonated products with neutral water molecules were also studied in order to gain an understanding of formation of their water clusters.

\section{Experiment}

\section{SIFT experiments}

The SIFT experiments ${ }^{22}$ were carried out using a Profile 3 instrument (Instrument Science, Crewe, UK). The $\mathrm{H}_{3} \mathrm{O}^{+}, \mathrm{NO}^{+}$ and $\mathrm{O}_{2}{ }^{+}$reagent ions were generated in a microwave discharge. One reagent ion type was mass selected using a quadrupole mass filter at a time and injected into the $5 \mathrm{~cm}$ long flow tube where a constant laminar flow of helium carrier gas was established at a total pressure of $1.5 \mathrm{mbar}$ and a temperature of $300 \mathrm{~K}$. Synthetic air containing the controlled amounts of neutral reagent vapours (phthalates and water vapour) was introduced into the flow tube by an inlet port located $1 \mathrm{~cm}$ downstream from the ion injector at a flow rate of $20 \mathrm{~mL} \mathrm{~min}{ }^{-1}$. Depending on the type of the reagent ions, the ionization of phthalate molecules (M) may occur at thermal energy via several channels: proton transfer typical for reaction with $\mathrm{H}_{3} \mathrm{O}^{+}$reagent ions

$$
\mathrm{H}_{3} \mathrm{O}^{+}+\mathrm{M} \rightarrow \mathrm{MH}^{+}+\mathrm{H}_{2} \mathrm{O}
$$

charge transfer, characteristic for $\mathrm{O}_{2}{ }^{+}$reagent ions

$$
\mathrm{O}_{2}^{+}+\mathrm{M} \rightarrow \mathrm{M}^{+}+\mathrm{O}_{2},
$$

and association forming an ion adduct, typical for primary reactions with $\mathrm{NO}^{+}$reagent ions or secondary reactions of ions with water

$$
\mathrm{NO}^{+}+\mathrm{M}+\mathrm{He} \rightarrow \mathrm{MNO}^{+}+\mathrm{He}
$$

The product ions were sampled at the end of the flow tube, mass analysed using the downstream quadrupole mass filter and detected using an electron multiplier. Data were collected from full scan mass spectra (MS) and the multi-ion monitoring (MIM) mode was used to monitor the product ion distribution during the controlled humidity change.

\section{Gases and chemicals}

The investigated phthalates DMP (dimethyl phthalate, CAS: 131-11-3), DMIP (dimethyl isophthalate, CAS: 1459-93-4), DMTP (dimethyl terephthalate, CAS: 120-61-6), DEP (diethyl phthalate, CAS: 84-66-2), DPP (dipropyl phthalate, CAS: 131-16-8) and DBP (dibutyl phthalate, CAS: 84-74-2) were purchased from SigmaAldrich as reagents with stated 99\% purity.

To characterize the product ion composition via mass spectrometry, a few mg of phthalate sample was placed at the bottom of a $15 \mathrm{~mL}$ glass vial closed by aluminium foil and heated up to $T=370 \mathrm{~K}$. The volume of the vial containing phthalate vapours was then sampled directly via SIFT-MS. The humidification of the sample was difficult in this setup. Thus, we carried out the measurements only with synthetic and laboratory air.

To confirm the identity of the product ions, phthalate vapours were also deposited on the inner surface of a $2 \mathrm{~m}$ long, $0.25 \mathrm{~mm}$ ID polyether ether ketone (PEEK) capillary heated up to $T=360 \mathrm{~K}$. This capillary was then flushed by a flow rate of

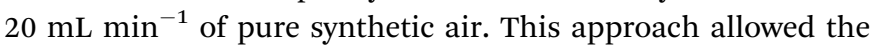
suppression of highly volatile impurities and the spectra so obtained were much cleaner, containing only the clean phthalate product ion peaks. Peaks that disappeared (i.e. $\mathrm{m} / \mathrm{z} 57$, 75 and 93 in DDP using $\mathrm{H}_{3} \mathrm{O}^{+}$, see the $\mathrm{ESI} \dagger$ ) were considered to originate from volatile impurities.

To study the influence of humidity on phthalate ion chemistry, we used the diffusion tube method. ${ }^{23}$ A few $\mathrm{mg}$ of phthalate sample was placed in a $2 \mathrm{~mL}$ vial closed by polytetrafluoroethylene (PTFE) septum caps penetrated with a diffusion tube $\left(1 / 16^{\prime \prime}\right.$ OD $\times 0.25 \mathrm{~mm}$ ID $\times 5 \mathrm{~cm}$ length PEEK capillary). The $2 \mathrm{~mL}$ vial was then placed in a $15 \mathrm{~mL}$ glass vial closed by a PTFE septum. The headspace of the $15 \mathrm{~mL}$ vial was sampled directly via SIFT-MS. Individual samples were heated up to $T=370 \mathrm{~K}$ to enhance their evaporation. Synthetic air was used to refill the air in the vial sampled via SIFT-MS. The humidity of synthetic air was controlled using an in-line water reservoir using the diffusion tube method. The water temperature within the reservoir was varied between $T=77 \mathrm{~K}$ and $T=350 \mathrm{~K}$. The resulting water vapor concentration ranged from $10^{12}$ to $10^{14}$ molecules per $\mathrm{cm}^{3}$. These water vapor concentrations were estimated according to the hydronium water cluster distribution via SIFT-MS as described elsewhere. ${ }^{24,25}$ The relative value of the water vapor concentration is calculated using the following dimensionless logarithmic factor

$$
H=\ln \left(\frac{\left[\mathrm{H}_{3} \mathrm{O}^{+}\right]+\left[\mathrm{H}_{3} \mathrm{O}^{+} \cdot \mathrm{H}_{2} \mathrm{O}\right]+\left[\mathrm{H}_{3} \mathrm{O}^{+} \cdot\left(\mathrm{H}_{2} \mathrm{O}\right)_{2}\right]+\cdots}{\left[\mathrm{H}_{3} \mathrm{O}^{+}\right]}\right)
$$

Eqn (4) allows us to better compare the obtained experimental results. 


\section{Results and discussion}

\section{Molecular properties}

The properties of three DMP isomer molecules and of the DEP molecule are given in Table 1. The quantification of DMP isomers using chemical ionization in the $\mathrm{H}_{3} \mathrm{O}^{+}$reactions is feasible as their proton affinity (PA) is $>1.5 \mathrm{eV}$ that of water molecules $\left(\mathrm{PA}\left(\mathrm{H}_{2} \mathrm{O}\right)=7.2 \mathrm{eV}^{26}\right)$. Note that proton transfer is possible also from the hydrated hydronium ion as $\mathrm{PA}\left(\left(\mathrm{H}_{2} \mathrm{O}\right)_{2}\right)=$ $8.56 \mathrm{eV} .{ }^{17}$ In addition, charge transfer from $\mathrm{O}_{2}{ }^{+}$is also possible due to the ionisation potential being lower than that of $\mathrm{O}_{2}$. As the PA of all three DMP isomers exceeds the PA of $\mathrm{H}_{2} \mathrm{O}$, the rate constant for proton transfer $(k)$ is equal to the collisional rate constant $\left(k_{\mathrm{c}}\right) .^{27}$ The $k_{\mathrm{c}}$ can be calculated for the $\mathrm{H}_{3} \mathrm{O}^{+}$reactions using the parametrised trajectory formulation described by $\mathrm{Su}$ and Chesnavich $^{18}$ (see Table 1) using the polarizabilities and dipole moments of the molecules. These parameters were obtained by quantum chemical calculations $(\omega \mathrm{b} 97 \mathrm{xd} / 6-311+\mathrm{G}(2 \mathrm{~d}, \mathrm{p}))$ related to previous IMS studies of these DMP isomers. ${ }^{17}$

\section{Ion molecule reaction products}

Using the SIFT method, we have studied the ion chemistry of individual DMP isomers, DEP, DMP and DBP using $\mathrm{H}_{3} \mathrm{O}^{+}, \mathrm{NO}^{+}$ and $\mathrm{O}_{2}{ }^{+}$reagent ions. The observed ion products are summarized in Table 2. All $\mathrm{H}_{3} \mathrm{O}^{+}$reactions led to the formation of protonated phthalates (1) and a loss of one alkyloxy substituent (OR, where $\mathrm{R}$ stands for alkyl radicals). This dissociation channel, forming $(\mathrm{M}-\mathrm{OR})^{+}$ions, was observed for all phthalate reactions. Protonated phthalate anhydride $\left(m / z 149, \mathrm{PhA} \cdot \mathrm{H}^{+}\right)$ was a minor product only for DPP and DBP.

For the $\mathrm{NO}^{+}$reactions, association (reaction (3)) was observed for all phthalates except DBP, where the adduct mass exceeded the upper limit of the downstream quadrupole mass filter $(\mathrm{m} / \mathrm{z} 300)$. DBP. $\mathrm{NO}^{+}$is likely to be a dominant product (as for the smaller phthalates) and thus the product ratio cannot be determined and only the upper limits are given in Table 2 . The protonated molecule $\mathrm{MH}^{+}$was observed for all phthalates and,

Table 1 Summary of the ionization energies (IEs) and the proton affinities (PAs) of reactants together with estimated rate coefficients for reactions of $\mathrm{H}_{3} \mathrm{O}^{+}$

\begin{tabular}{lllllll}
\hline Molecule & $m(\mathrm{u})$ & $\mathrm{IE}(\mathrm{eV})$ & $\mathrm{PA}(\mathrm{eV})$ & $\begin{array}{l}\alpha \\
\left(10^{-24} \mathrm{~cm}^{3}\right)\end{array}$ & $\mu(\mathrm{D})$ & $\begin{array}{l}k_{\mathrm{c}}\left(\mathrm{H}_{3} \mathrm{O}^{+}\right) \\
\left(10^{-9} \mathrm{~cm}^{3} \mathrm{~s}^{-1}\right)\end{array}$ \\
\hline DMP & 194 & $9.64^{a}$ & $9.7^{c}$ & $23.99^{c}$ & $0.26^{c}$ & 2.82 \\
DMIP & 194 & $9.84^{a}$ & $8.74,^{b} 8.77^{c}$ & $24.84^{c}$ & $1.9^{c}$ & 3.63 \\
DMTP & 194 & $9.78^{a}$ & $8.74,^{b} 8.74^{c}$ & $28.71^{c}$ & $0^{c}$ & 3.02 \\
DEP & 222 & nd & nd & $\sim 23^{d}$ & nd & nd \\
DPrP & 250 & nd & nd & nd & nd & nd \\
DBP & 278 & nd & nd & nd & nd & nd
\end{tabular}

Presented also are the monoisotopic molecular weight, $m$, in atomic units $\mathrm{u}$, polarizability $\alpha$, in units of $10^{-24} \mathrm{~cm}^{3}$ and permanent dipole moment $\mu$, in Debye, D. The values of $\alpha$ and $\mu$ are taken from a report by Michalczuk et al. ${ }^{17}$ based on private communications and post analysis of their data at the $\omega \mathrm{b} 97 \mathrm{xd} / 6-311+\mathrm{G}(2 \mathrm{~d}, \mathrm{p})$ level of theory. The collision rate coefficient $k_{\mathrm{c}}$ was calculated according to the parameterised trajectory formulation put forth by $\mathrm{Su}$ and Chesnavich. ${ }^{18}$ For additional references: ${ }^{a}$ Ref. 19. ${ }^{b}$ Ref. 20. ${ }^{c}$ Ref. 17. ${ }^{d}$ ChemSpider predicted properties, ${ }^{21}$ nd - no data. as will be discussed later, we consider this to be a product of the $\mathrm{M} \cdot \mathrm{NO}^{+}$secondary reaction with water vapour. Other fragments including protonated phthalate anhydride and $(\mathrm{M}-(\mathrm{R}-2 \mathrm{H}))^{+}$ were detected with low intensity.

Finally, $\mathrm{O}_{2}{ }^{+}$reactions proceeded via charge transfer (reaction (2)). The molecular ion is dominant only for the ortho and para DMP isomers. The $(\mathrm{M}-\mathrm{OR})^{+}$ion fragment was formed for all DMP isomers. The production of $(\mathrm{M}-(\mathrm{R}-2 \mathrm{H}))^{+}$becomes dominant for phthalates with longer alkyl chains, and it is accompanied by the formation of protonated phthalic acid $\left(\mathrm{m} / \mathrm{z} 167,\left(\mathrm{PhA} \cdot \mathrm{H}+\mathrm{H}_{2} \mathrm{O}\right)^{+}\right)$ and protonated phthalate anhydride $\left(\mathrm{m} / z\right.$ 149, $\left.\mathrm{PhA} \cdot \mathrm{H}^{+}\right)$.

The observed ion chemistry may be compared with previous studies of chemical ionization reactions of phthalates, using CI reagents such as methane and isobutane, ${ }^{28}$ methane and ammonia $^{12}$ and methane. ${ }^{29}$ Chemical ionisation reactions involving isobutane and ammonia were found to produce mostly the protonated phthalate ions. For methane, the CI reaction leads to protonated phthalate anhydrides $(\mathrm{m} / \mathrm{z} 149)$ since the PA of methane $(5.6 \mathrm{eV})$ is much lower than the PAs of phthalates. Note that in electron ionization, ${ }^{30}$ this ion $(\mathrm{m} / z \mathrm{149})$ is also often dominant. The formation of protonated phthalate anhydride was well explained by theoretical calculations of Jeilani et al. studying protonated ${ }^{29}$ and ionised $^{31}$ phthalates. Protonated phthalate anhydride is generated from protonated phthalates via two pathways, initiated by the dissociation of alkyl or alcohol:

$$
\begin{gathered}
\mathrm{MH}^{+} \rightarrow[\mathrm{M}-\mathrm{OR}]^{+}+\mathrm{HOR} \\
\mathrm{MH}^{+} \rightarrow[\mathrm{M}-(\mathrm{R}-2 \mathrm{H})]^{+}+(\mathrm{R}-\mathrm{H})
\end{gathered}
$$

First, the loss of an alcohol molecule (5), common for all phthalates, leads to the formation of protonated phthalate anhydride directly. The second reaction (6) proceeds via a McLafferty rearrangement, ${ }^{32}$ which requires a $\mathrm{C}_{2}$ or longer alkyl ligand to be present in the phthalate ester group. From there, formation of the $(\mathrm{M}-(\mathrm{R}-2 \mathrm{H}))^{+}$fragment leads to protonated phthalic acid $\left(\mathrm{m} / \mathrm{z} 167,\left(\mathrm{PhA} \cdot \mathrm{H}+\mathrm{H}_{2} \mathrm{O}\right)^{+}\right)$and then to $\mathrm{m} / \mathrm{z} 149$ by $\mathrm{H}_{2} \mathrm{O}$ loss. The change of the free energy for the case of DBP favours reaction (6) by $12.2 \mathrm{~kJ} \mathrm{~mol}^{-131}$ as calculated at the B3LYP/6-311G(d,p) level of theory.

Both pathways were identified in the CI spectra of most phthalates before; $(\mathrm{M}-\mathrm{OR})^{+}$ions are often more intense than $(\mathrm{M}-(\mathrm{R}-2 \mathrm{H}))^{+}$ions and the intensity of the $(\mathrm{M}-\mathrm{OR})^{+}$fragment decreases with increasing alkyl chain length. ${ }^{12}$ In contrast to these previous studies, in our present results, only traces of the specific products related to the McLafferty rearrangement were observed for DMIP and DBP. For phthalates with longer alkyl chains, even though the calculations indicated the McLafferty rearrangement to be energetically more favourable, the loss of alcohol is a much faster process when $\mathrm{H}_{3} \mathrm{O}^{+}$or methane ions are used.

Similar pathways were described for phthalate ions produced by $\mathrm{EI}^{30,31}$

$$
\begin{gathered}
\mathrm{M}^{+} \rightarrow[\mathrm{M}-\mathrm{OR}]^{+}+\mathrm{OR} \\
\mathrm{M}^{+} \rightarrow[\mathrm{M}-(\mathrm{R}-2 \mathrm{H})]^{+}+(\mathrm{R}-2 \mathrm{H})
\end{gathered}
$$

and these agree with the observed charge transfer reactions (2) of $\mathrm{O}_{2}{ }^{+}$reagent ions. The McLafferty rearrangement occurs for 
Table 2 lon products of phthalates interacting with $\mathrm{H}_{3} \mathrm{O}^{+}, \mathrm{NO}^{+}$and $\mathrm{O}_{2}{ }^{+}$reagent ions obtained via SIFT-MS. R stands for an alkyl substituent variating for different phthalates and PhA stands for the phthalate anhydride. Experiments were carried out in synthetic air. The ions in italic are products of secondary ion interaction with water vapour ${ }^{a}$

\begin{tabular}{|c|c|c|c|c|c|c|c|c|c|}
\hline \multirow[b]{2}{*}{ Compound (vapour pressure) } & \multicolumn{3}{|c|}{$\underline{\mathrm{H}_{3} \mathrm{O}^{+}}$} & \multicolumn{3}{|l|}{$\mathrm{NO}^{+}$} & \multicolumn{3}{|l|}{$\underline{\mathrm{O}}_{2}^{+}$} \\
\hline & $m / z$ & br & Ion & $m / z$ & br & Ion & $m / z$ & br & Ion \\
\hline $\operatorname{DMP}\left(4.1^{\mathrm{a}}\right)$ & $\begin{array}{l}163 \\
195\end{array}$ & $\begin{array}{l}75 \% \\
25 \%\end{array}$ & $\begin{array}{l}(\mathrm{DMP}-\mathrm{OR})^{+} \\
\mathrm{DMP}^{+} \mathrm{H}^{+}\end{array}$ & $\begin{array}{l}163 \\
195 \\
224\end{array}$ & $\begin{array}{l}86 \% \\
2 \% \\
11 \%\end{array}$ & $\begin{array}{l}(\mathrm{DMP}-\mathrm{OR})^{+} \\
D M P \cdot H^{+} \\
\mathrm{DMP} \cdot \mathrm{NO}^{+}\end{array}$ & $\begin{array}{l}163 \\
194\end{array}$ & $\begin{array}{l}83 \% \\
17 \%\end{array}$ & $\begin{array}{l}(\mathrm{DMP}-\mathrm{OR})^{+} \\
\mathrm{DMP}^{+}\end{array}$ \\
\hline $\operatorname{DMIP}\left(12.8^{\mathrm{a}}\right)$ & $\begin{array}{l}163 \\
181 \\
195 \\
213\end{array}$ & $\begin{array}{r}8 \% \\
1 \% \\
82 \% \\
9 \%\end{array}$ & $\begin{array}{l}(\mathrm{DMIP}-\mathrm{OR})^{+} \\
\left(\mathrm{DMIP} \cdot \mathrm{H}-\mathrm{CH}_{2}\right)^{+} \\
{\mathrm{DMIP} \cdot \mathrm{H}^{+}} \\
\mathrm{DMIP} \cdot \mathrm{H}^{+} \cdot \mathrm{H}_{2} \mathrm{O}\end{array}$ & $\begin{array}{l}163 \\
195 \\
224\end{array}$ & $\begin{array}{l}63 \% \\
9 \% \\
28 \%\end{array}$ & $\begin{array}{l}(\mathrm{DMIP}-\mathrm{OR})^{+} \\
D M I P \cdot H^{+} \\
\text {DMIP } \cdot \mathrm{NO}^{+}\end{array}$ & $\begin{array}{l}163 \\
194\end{array}$ & $\begin{array}{l}39 \% \\
61 \%\end{array}$ & $\begin{array}{l}(\mathrm{DMIP}-\mathrm{OR})^{+} \\
\mathrm{DMIP}^{+}\end{array}$ \\
\hline $\operatorname{DMTP}\left(14.1^{\mathrm{a}}\right)$ & $\begin{array}{l}163 \\
195 \\
213\end{array}$ & $\begin{array}{r}11 \% \\
82 \% \\
7 \%\end{array}$ & $\begin{array}{l}(\text { DMTP-OR })^{+} \\
\text {DMTP.H }{ }^{+} \\
\text {DMTP } \cdot H^{+} \cdot \mathrm{H}_{2} \mathrm{O}\end{array}$ & $\begin{array}{l}163 \\
195 \\
224\end{array}$ & $\begin{array}{l}79 \% \\
9 \% \\
11 \%\end{array}$ & $\begin{array}{l}(\mathrm{DMTP}-\mathrm{OR})^{+} \\
D M T P \cdot H^{+} \\
\mathrm{DMTP}^{+} \mathrm{NO}^{+}\end{array}$ & $\begin{array}{l}163 \\
194\end{array}$ & $\begin{array}{l}26 \% \\
74 \%\end{array}$ & $\begin{array}{l}(\mathrm{DMTP}-\mathrm{OR})^{+} \\
\mathrm{DMTP}^{+}\end{array}$ \\
\hline $\operatorname{DPP}\left(0.18^{\mathrm{c}}\right)$ & $\begin{array}{l}149 \\
163 \\
191 \\
251\end{array}$ & $\begin{array}{r}1 \% \\
1 \% \\
15 \% \\
83 \%\end{array}$ & $\begin{array}{l}\mathrm{PhA} \cdot \mathrm{H}^{+} \\
(\mathrm{DPP}-\mathrm{OR})^{+} \\
\mathrm{DPP} \cdot \mathrm{H}^{+}\end{array}$ & $\begin{array}{l}149 \\
191 \\
209 \\
251 \\
280\end{array}$ & $\begin{array}{l}1 \% \\
21 \% \\
2 \% \\
3 \% \\
73 \%\end{array}$ & 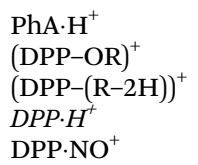 & $\begin{array}{l}149 \\
167 \\
191 \\
209 \\
250\end{array}$ & $\begin{array}{r}24 \% \\
6 \% \\
15 \% \\
47 \% \\
8 \%\end{array}$ & $\begin{array}{l}\mathrm{PhA} \cdot \mathrm{H}^{+} \\
\left(\mathrm{PhA} \cdot \mathrm{H}+\mathrm{H}_{2} \mathrm{O}\right)^{+} \\
(\mathrm{DPP}-\mathrm{OR})^{+} \\
(\mathrm{DPP}-(\mathrm{R}-2 \mathrm{H}))^{+} \\
\text {DPP }^{+}\end{array}$ \\
\hline $\operatorname{DBP}\left(0.027^{\mathrm{d}}\right)$ & $\begin{array}{l}149 \\
167 \\
205 \\
279\end{array}$ & $\begin{array}{r}6 \% \\
2 \% \\
9 \% \\
83 \%\end{array}$ & $\begin{array}{l}\mathrm{PhA} \cdot \mathrm{H}^{+} \\
\left(\mathrm{PhA} \cdot \mathrm{H}+\mathrm{H}_{2} \mathrm{O}\right)^{+} \\
(\mathrm{DBP}-\mathrm{OR})^{+} \\
\text {DBP } \cdot \mathrm{H}^{+}\end{array}$ & $\begin{array}{l}178 \\
205 \\
223 \\
279 \\
308\end{array}$ & $\begin{array}{l}<12 \% \\
<52 \% \\
<4 \% \\
<32 \% \\
?^{*}\end{array}$ & 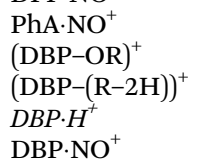 & $\begin{array}{l}149 \\
167 \\
205 \\
223 \\
278\end{array}$ & $\begin{array}{r}24 \% \\
7 \% \\
13 \% \\
34 \% \\
22 \%\end{array}$ & $\begin{array}{l}\mathrm{PhA} \cdot \mathrm{H}^{+} \\
\left(\mathrm{PhA} \cdot \mathrm{H}+\mathrm{H}_{2} \mathrm{O}\right)^{+} \\
(\mathrm{DBP}-\mathrm{OR})^{+} \\
(\mathrm{DBP}-(\mathrm{R}-2 \mathrm{H}))^{+} \\
\text {DBP }^{+}\end{array}$ \\
\hline
\end{tabular}

${ }^{a} \mathrm{br}$ - branching ratio, vapour pressure is stated in units of $10^{-3}$ mbar at $25{ }^{\circ} \mathrm{C}$ according to (a) Daubert and Thomas, ${ }^{33}$ (b) Hinckley et al., ${ }^{34}$ (c) $\mathrm{EPA}^{35}$ and (d) Donovan. ${ }^{36} * \mathrm{~m} / \mathrm{z} 308$ is out of the $\mathrm{m} / \mathrm{z}$ range of SIFT-MS.

DEP, and becomes dominant for DPP and DBP. For DBP, the activation energy calculated by B3LYP/6-311G $(\mathrm{d}, \mathrm{p})^{31}$ for $(8)$ is only $23 \mathrm{~kJ} \mathrm{~mol}^{-1}$, and it is $97.3 \mathrm{~kJ} \mathrm{~mol}^{-1}$ to produce $\mathrm{PhA} \cdot \mathrm{H}^{+}$. The loss of alkoxyl requires $42.3 \mathrm{~kJ} \mathrm{~mol}^{-1}$ for (7), and $130 \mathrm{~kJ} \mathrm{~mol}^{-1}$ is required to produce $\mathrm{PhA} \cdot \mathrm{H}^{+}$. Our present studies follow this precedence, and fragments related to (8) can be observed for DEP and become dominant for DPP and DBP.

In the $\mathrm{NO}^{+} \mathrm{CI}$ reactions, the observed $(\mathrm{M}-\mathrm{OR})^{+}$fragments cannot result from the dissociative charge transfer, as IE $(\mathrm{NO})=$ $9.26 \mathrm{eV}^{26}$ is below the IE of DMP isomers and must proceed by the formation of a neutral RONO product from the reaction intermediate $\mathrm{MNO}^{+}$. A similar process was observed previously for the $\mathrm{M} \cdot \mathrm{C}_{2} \mathrm{H}_{5}{ }^{+}$adducts. ${ }^{29}$ In our present studies, the only observed fragment adduct ion was $\mathrm{PhA} \cdot \mathrm{NO}^{+}$resulting from the $\mathrm{NO}^{+}$reaction with DBP. An interesting observation is the presence of a small amount of $(\mathrm{M}-(\mathrm{R}-2 \mathrm{H}))^{+}$fragments, as these are typical for McLafferty rearrangement. For $\mathrm{M} \cdot \mathrm{C}_{2} \mathrm{H}_{5}{ }^{+}$adducts, this rearrangement occurred in a reaction sequence after the initial dissociation of an alkyl substituent, while in the present study, it is a separate $\mathrm{NO}^{+}$reaction channel. The presence of protonated phthalate was also observed for $\mathrm{M} \cdot \mathrm{C}_{2} \mathrm{H}_{5}{ }^{+}$adducts and it was explained by the dissociation of neutral $\mathrm{C}_{2} \mathrm{H}_{4}$ obtained from the adduct. This process is not possible for $\mathrm{NO}^{+}$ions. However, the protonated phthalate can be formed via secondary reactions with water vapour, which will be explained later.

\section{Secondary reactions with water vapour}

In the second part of the work, we have studied the influence of humidity on the ion chemistry of individual phthalates by changing the water vapour concentration within the flow tube. The presence of water vapour affects the ion chemistry in several ways. First, the reagent ions form water clusters and this changes their facility to ionise other organic molecules. In SIFT-MS, $\mathrm{H}_{3} \mathrm{O}^{+}$ reagent ions are the most affected, where reactions

$$
\mathrm{H}_{3} \mathrm{O}^{+}\left(\mathrm{H}_{2} \mathrm{O}\right)_{n-1}+\mathrm{H}_{2} \mathrm{O}+\mathrm{He} \leftrightarrow \mathrm{H}_{3} \mathrm{O}^{+}\left(\mathrm{H}_{2} \mathrm{O}\right)_{n}+\mathrm{He}
$$

can form clusters with $n$ up to 4 . This effect is illustrated in Fig. 1, showing the relative distribution of hydronium water clusters as a function of water vapour concentration. Second, water clusters formed from protonated organic molecules may lead to complicated ion chemistry, compromising SIFT-MS selectivity and detection limits. Finally, at higher concentrations, water vapour may increase the rate of adduct formation.

The influence of water vapour on ion chemistry has been investigated in the present experiments for all reagent ions. For the $\mathrm{NO}^{+}$reagent ions, we observed an increase in the relative intensity for the $\mathrm{MH}^{+}$ions (by 5-10\%) with water vapour concentration. This $\mathrm{MH}^{+}$intensity is too great to be produced by proton transfer from the $(\sim 1 \%)$ amount of $\mathrm{H}_{3} \mathrm{O}^{+}$ions present in the flow tube together with the $\mathrm{NO}^{+}$ions. Based on 


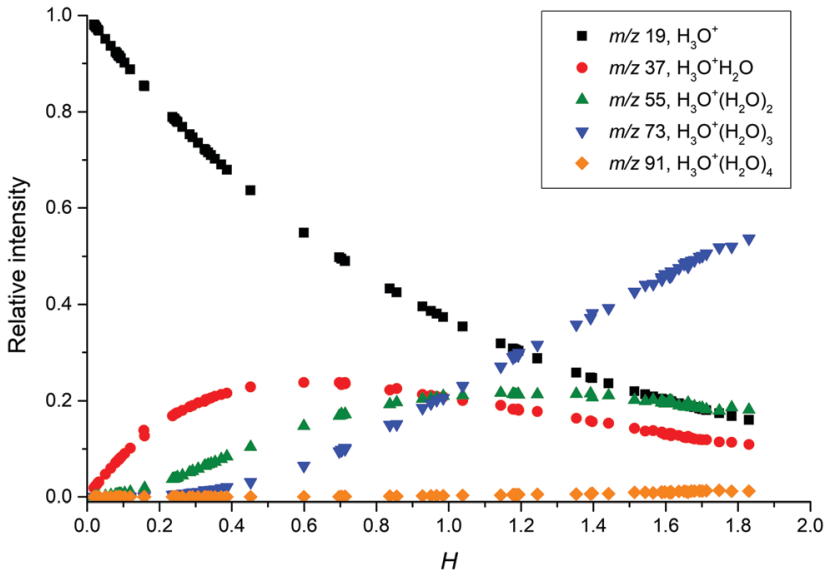

Fig. 1 Relative distribution of hydronium reagent ions based on different water concentrations in the flow tube.

its increase with water vapour concentration, we suggest that it can be produced via a secondary reaction with the phthalate$\mathrm{NO}^{+}$adduct.

$$
\mathrm{M} \cdot \mathrm{NO}^{+}+\mathrm{H}_{2} \mathrm{O} \rightarrow \mathrm{MH}^{+}+\mathrm{HONO}
$$

Reaction (10) can only take place if the proton affinity of phthalate (M) sufficiently exceeds the $\mathrm{NO}^{+}$affinity, as the notional reaction

$$
\mathrm{NO}^{+}+\mathrm{H}_{2} \mathrm{O} \rightarrow \mathrm{H}^{+}+\mathrm{HONO}
$$

is $711 \mathrm{~kJ} \mathrm{~mol}^{-1}$ endothermic. $^{26}$ The proton affinity is known only for the DMP isomers (see Table 1 ) while the $\mathrm{NO}^{+}$affinity can only be estimated. The typical $\mathrm{NO}^{+}$affinities ${ }^{37}$ of organic molecules range from 100 to $200 \mathrm{~kJ} \mathrm{~mol}^{-1}$. A linear correlation between $\mathrm{PA}$ and $\mathrm{NO}^{+}$affinity can be used, but it depends on whether the $\mathrm{NO}^{+}$association gives a $\sigma$ or $\pi$ complex. ${ }^{37}$ For DMP, such a correlation estimates a $\mathrm{NO}^{+}$affinity of $169 \mathrm{~kJ} \mathrm{~mol}^{-1}$ for the $\sigma$ complex $\left(222.6 \mathrm{~kJ} \mathrm{~mol}^{-1}\right.$ for $\pi$ ). Both these estimates are well below the $\mathrm{PA}(\mathrm{DMP})=935.9 \mathrm{~kJ} \mathrm{~mol}^{-1}$ and render reaction (10) exothermic by 56.3 (or 2.7 ) $\mathrm{kJ} \mathrm{mol}^{-1}$. For the meta and para isomers, reaction (10) would be endothermic by 4.7 (or 39.4) $\mathrm{kJ} \mathrm{mol}^{-1}$. Despite this, the high number density of water molecules in the carrier gas $\left(10^{12}-10^{14} \mathrm{~cm}^{-3}\right)$ can shift the reaction equilibrium in favour of $\mathrm{MH}^{+}$production.

Finally, the secondary reactions of the $\mathrm{O}_{2}{ }^{+}$products can be discussed. A notable effect was observed only for DEP, DPP and DBP. Increasing the water vapour concentration led to a decrease in the fragmentation rate of the protonated phthalate anhydride $(\mathrm{m} / \mathrm{z} 149)$ by $5-10 \%$, compensated by an increase of protonated phthalate acid $(\mathrm{m} / \mathrm{z} 167)$ intensity.

For the $\mathrm{H}_{3} \mathrm{O}^{+}$reagent ions, the change in the relative distribution of the phthalate product ions for different water vapour concentrations is shown in Fig. 2. The formation of protonated phthalate water clusters depends strongly on the location of esters in the phthalate structure. In the ortho position, protonated phthalate hydrates are not produced at all. However, for DMIP (phthalate ester in the meta position),
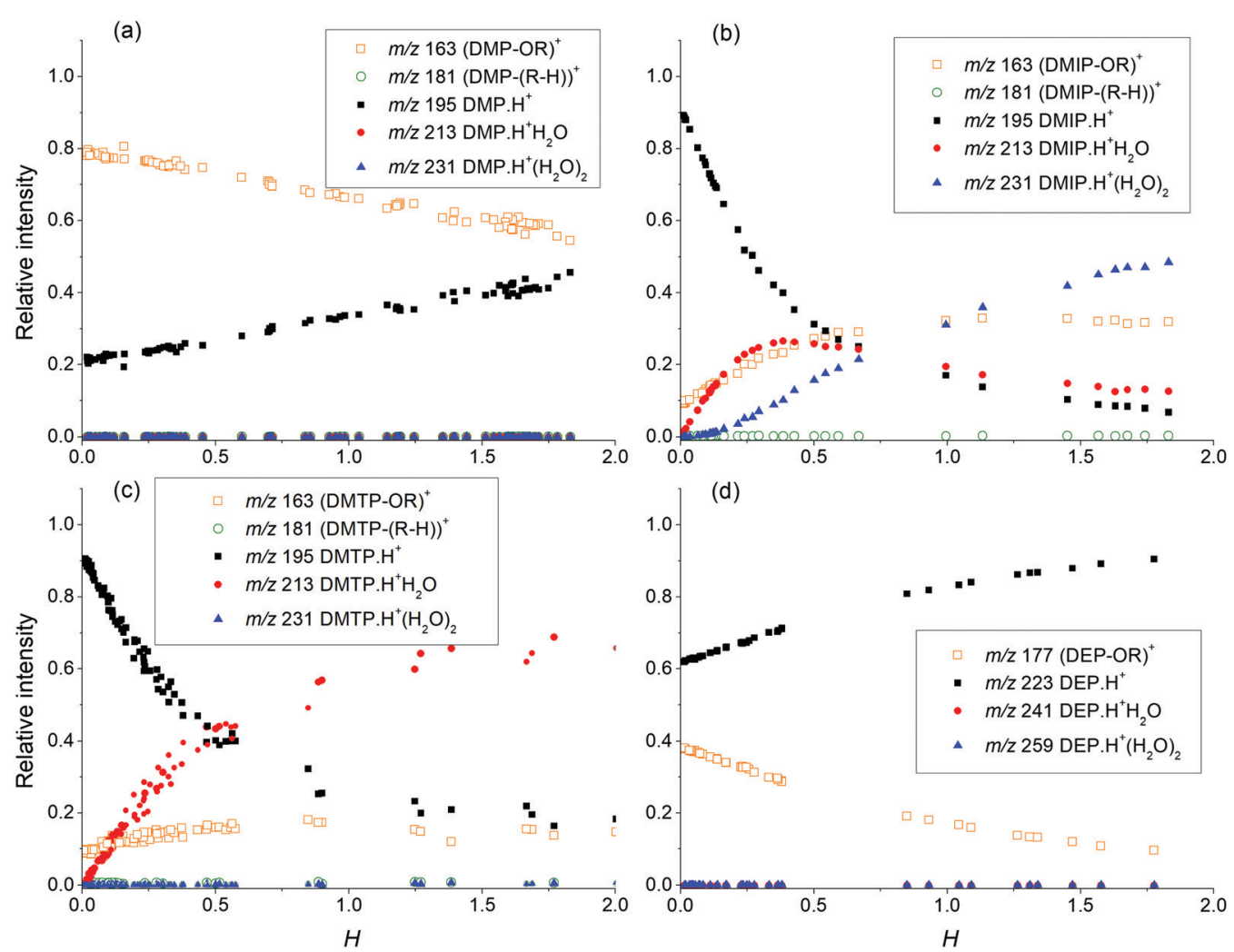

(d)

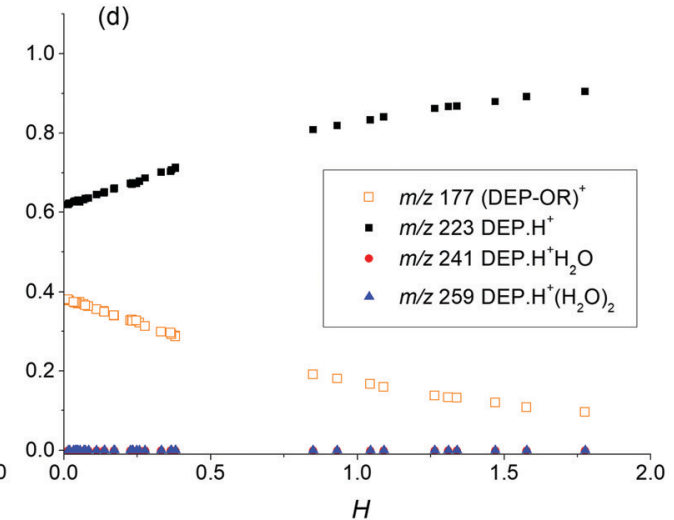

Fig. 2 Relative ion ratio between the observed products of phthalate molecules (a) DMP, (b) DMIP, (c) DMTP, and (d) DEP based on the relative water concentration in the flow tube $H$. 
Table 3 Calculated changes of Gibbs free energies for individual proton transfer reactions and adduct formation reactions of DMP isomers (M) with different reagent ions. Data taken from ref. 17

\begin{tabular}{lllll}
\hline Reagent ion & Products & DMP $(\mathrm{eV})$ & DMIP $(\mathrm{eV})$ & DMTP $(\mathrm{eV})$ \\
\hline $\mathrm{H}_{3} \mathrm{O}^{+}$ & $\mathrm{MH}^{+}+\mathrm{H}_{2} \mathrm{O}$ & -2.445 & -1.678 & -1.572 \\
$\mathrm{H}_{3} \mathrm{O}^{+}\left(\mathrm{H}_{2} \mathrm{O}\right)$ & $\mathrm{MH}_{3} \mathrm{O}^{+}+\mathrm{H}_{2} \mathrm{O}$ & -1.283 & $-\mathbf{0 . 9 0 8}$ & $-\mathbf{0 . 7 9 3}$ \\
& $\mathrm{MH}^{+}+\left(\mathrm{H}_{2} \mathrm{O}\right)_{2}$ & -1.156 & -0.389 & -0.282 \\
$\mathrm{H}_{3} \mathrm{O}^{+}\left(\mathrm{H}_{2} \mathrm{O}\right)_{2}$ & $\mathrm{MH}_{2} \mathrm{OH}_{3} \mathrm{O}^{+}+\mathrm{H}_{2} \mathrm{O}$ & -0.627 & $-\mathbf{0 . 7 5 6}$ & -0.338 \\
& $\mathrm{MH}_{3} \mathrm{O}^{+}+\left(\mathrm{H}_{2} \mathrm{O}\right)_{2}$ & -0.560 & -0.184 & -0.070 \\
& $\mathrm{MH}^{+}+\left(\mathrm{H}_{2} \mathrm{O}\right)_{3}$ & -0.513 & 0.255 & 0.361 \\
$\mathrm{H}_{3} \mathrm{O}^{+}\left(\mathrm{H}_{2} \mathrm{O}\right)_{3}$ & $\mathrm{M}\left(\mathrm{H}_{2} \mathrm{O}\right)_{2} \mathrm{H}_{3} \mathrm{O}^{+}+\mathrm{H}_{2} \mathrm{O}$ & -0.156 & -0.579 & -0.204 \\
& $\mathrm{MH}_{2} \mathrm{OH}_{3} \mathrm{O}^{+}+\left(\mathrm{H}_{2} \mathrm{O}\right)_{2}$ & -0.076 & -0.205 & 0.213 \\
& $\mathrm{MH}_{3} \mathrm{O}^{+}+\left(\mathrm{H}_{2} \mathrm{O}\right)_{3}$ & -0.089 & 0.286 & 0.401 \\
& $\mathrm{MH}^{+}+\left(\mathrm{H}_{2} \mathrm{O}\right)_{4}$ & -0.124 & 0.642 & 0.728
\end{tabular}

the formation of protonated phthalate water clusters can proceed to a degree of up to two water molecules per ion. Finally, for DMTP (phthalate esters in the para position), only one water molecule is observed to be attached to the protonated DMTP. The observed trend agrees with the APCI-IMS study of DMP isomers that was theoretically explained. ${ }^{17}$ For $\mathrm{DMP} \cdot \mathrm{H}^{+}$, the proton is located between the two carboxyl oxygens of phthalate esters, independent of the amount of $\mathrm{H}_{2} \mathrm{O}$ molecules.

The formation of the protonated DMP hydrates is energetically possible (see Table 3 ). However, due to the minimal energy difference between the individual hydration states and high number density of water molecules, equilibrium will be established through ligand switching reactions

$$
\mathrm{MH}^{+}\left(\mathrm{H}_{2} \mathrm{O}\right)_{n-1}+\mathrm{H}_{2} \mathrm{O} \leftrightarrow \mathrm{MH}^{+}+n\left(\mathrm{H}_{2} \mathrm{O}\right)
$$

where $n>0$, in favour of the protonated phthalate. For DMIP and DMTP isomers, the formation of $\mathrm{H}_{2} \mathrm{O}$ adducts is favoured, due to the deeper energetic minimum for DMIP. $\mathrm{H}_{3} \mathrm{O}^{+}$, DMIP. $\mathrm{H}_{3} \mathrm{O}^{+} \mathrm{H}_{2} \mathrm{O}$ and DMTP. $\mathrm{H}_{3} \mathrm{O}^{+}$formation. This is in excellent agreement with our observation. Data in Table 1 indicate that the protonated phthalate clusters may achieve even higher levels of hydration, however the direct formation of individual ions via primary switching reactions

$$
\mathrm{H}_{3} \mathrm{O}\left(\mathrm{H}_{2} \mathrm{O}\right)_{n-1}+\mathrm{M} \leftrightarrow \mathrm{MH}^{+}\left(\mathrm{H}_{2} \mathrm{O}\right)_{m-n}+n\left(\mathrm{H}_{2} \mathrm{O}\right)
$$

where $n, m>0$ becomes inefficient for higher hydronium water clusters. Additional hydration is possible due to the secondary association reactions of phthalate ions with water molecules

$$
\mathrm{MH}^{+}\left(\mathrm{H}_{2} \mathrm{O}\right)_{n-1}+\mathrm{H}_{2} \mathrm{O}+\mathrm{He} \leftrightarrow \mathrm{MH}^{+}\left(\mathrm{H}_{2} \mathrm{O}\right)_{n}+\mathrm{He}
$$

where $n>0$.

Using the numerical simulation software KIMI developed by the first author of this paper, ${ }^{38}$ it is possible to model the contribution of the individual reactions taking place in SIFT. Taking into account the relative ion distribution of protonated phthalate ions (Fig. 3), it is possible to interpret the observed
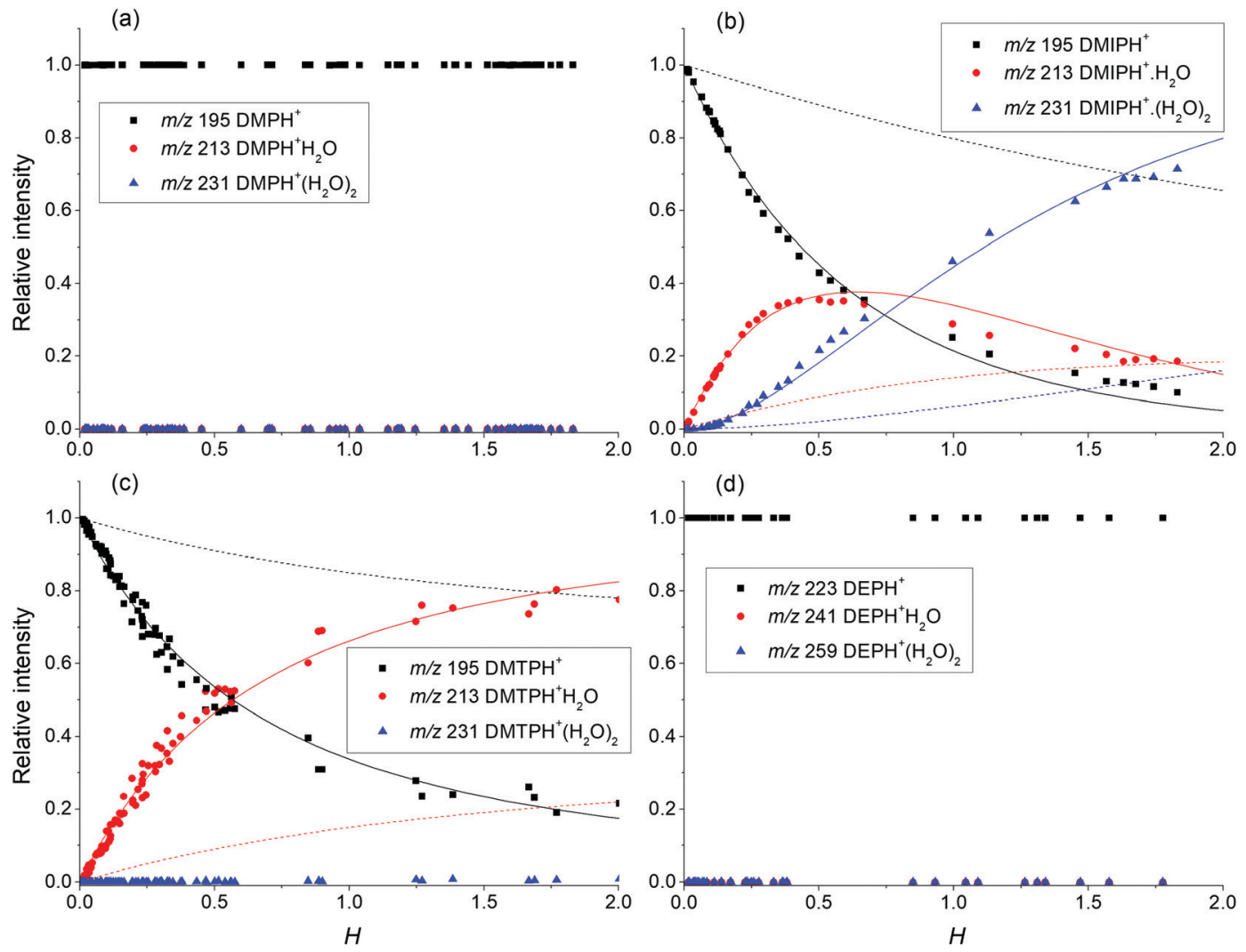

Fig. 3 Relative ion ratio between the protonated phthalate molecules (a) DMP, (b) DMIP, (c) DMTP, and (d) DEP, and their water clusters based on the relative water concentrations in the flow tube $H$. The relative distributions of DMIP and DMTP are supplemented by the simulation of ion kinetics using KIMI (ref. 38). The dash line represents a solution containing only proton transfer and adduct formation from hydronium clusters (reaction (13)). The solid line represents the previous solution obtained by the association of protonated phthalates with water (reaction (14)). 
profile considering only proton transfer from hydronium reagent ions $\left(\mathrm{H}_{3} \mathrm{O}^{+}\right)$and secondary interaction of protonated phthalates with water according to (14). Thus, in CI, where multiple hydronium water clusters as reagent ions are present, higher protonated phthalate water clusters will be formed mainly by the hydration of smaller water clusters rather than by direct switching reactions of $\mathrm{H}_{3} \mathrm{O}^{+}\left(\mathrm{H}_{2} \mathrm{O}\right)_{n}$. This agrees with previous SIFT results for a series of aldehydes. ${ }^{39}$ Finally, formation of the $(\mathrm{M}-\mathrm{OR})^{+}$fragment is affected by different concentrations of water vapour in SIFT as well. Fig. 2 shows a similar trend for DMP and DEP, where dissociation at higher water concentrations decreases as hydronium ions are replaced by less reactive hydronium water clusters. For DPP, DBP and DMTP, the dissociation was not affected by the presence of water vapour. The opposite trend can be observed for DMIP, where fragmentation rates increase with water vapour concentration. As the reactivity for higher hydronium water clusters decreases with the level of hydration, increased fragmentation can be explained by an additional secondary reaction. This reaction is probably initiated by the formation of a protonated phthalate-water complex, observed only for DMIP and DMTP, in a specific electronic state providing specific repulsive potential leading to

$$
\left[\mathrm{MH}^{+}\left(\mathrm{H}_{2} \mathrm{O}\right)_{n-1}\right]^{\#} \rightarrow(\mathrm{M}-\mathrm{OR})^{+}+\mathrm{HOR} \cdot\left(\mathrm{H}_{2} \mathrm{O}\right)_{n}
$$

where $n>1$. As we cannot determine details of this process, further study is required to fully understand this reaction.

\section{Conclusions}

New data were obtained on the kinetics of reactions involving $\mathrm{H}_{3} \mathrm{O}^{+}, \mathrm{NO}^{+}$and $\mathrm{O}_{2}{ }^{+}$ions with phthalate isomers DMP, DMIP and DMTP, DEP, DPP and DBP, including information on the primary and some secondary ion products using SIFT at different concentrations of water vapour. Different ion-molecule reaction channels were observed for the individual reagent ions, including a characteristic dissociation channel forming $(\mathrm{M}-\mathrm{OR})^{+}$ions. This dissociation channel has been observed in previous CI and EI studies for several phthalates and its dominance can be explained for the DMP isomers and DEP by the short length of the alkyl substituents. For DPP and DBP containing longer alkyl chains, products characteristic of the McLafferty rearrangement were dominant only for the $\mathrm{O}_{2}^{+}$reagent ions.

A strong effect of the DMP isomeric structure on the formation of the protonated phthalate water clusters was revealed. For the ortho DMP molecules, hydration of protonated molecules is not effective due to the small energy difference between the individual hydration levels. The high number density of water molecules moves the reaction equilibrium in favour of the dominant formation of protonated DMP.

For the DMIP and DMTP isomers, the energy levels for water cluster formation are more different, facilitating the formation of DMIP. $\mathrm{H}_{3} \mathrm{O}^{+}$, DMIP. $\mathrm{H}_{3} \mathrm{O}^{+} \mathrm{H}_{2} \mathrm{O}$ and DMTP $\cdot \mathrm{H}_{3} \mathrm{O}^{+}$water clusters. Using numerical simulation, we show that under the given SIFT conditions, phthalate water clusters are preferably formed by sequential hydration of protonated phthalates (14) rather than by direct ligand switching from hydronium water clusters (13). An increasing fragmentation rate at increasing water vapour concentrations observed for DMIP indicates the presence of an additional dissociation channel, producing $(\mathrm{M}-\mathrm{OR})^{+}$fragments from the generated protonated phthalate clusters. For DMP and DEP (phthalate esters in the ortho position), the protonated phthalate water clusters are not observed and the dissociation rate decreases with increasing water vapour concentration.

This detailed SIFT study of ion chemistry thus demonstrated that it is possible to analyse phthalates using different SIFT-MS ionization mechanisms. In addition, the humidity of the sample does not affect the ion chemistry for the studied ortho phthalates. As the proton is located between the two carboxyl oxygens of phthalate esters, the same effect is expected for the other phthalates as well. The effect of humidity on DMIP and DMTP can be additionally used to differentiate individual phthalate isomers via SIFT-MS.

\section{Conflicts of interest}

There are no conflicts to declare.

\section{Acknowledgements}

We would like to thank P. Papp for quantum chemical calculations $(\omega b 97 x d / 6-311+G(2 d, p))$ of polarizabilities and dipole moments of the DMP isomers. This project has received funding from the European Union's Horizon 2020 research and innovation programme under the Marie Skłodowska-Curie grant agreement no. 674911.

\section{Notes and references}

1 R. U. Halden, Annu. Rev. Public Health, 2010, 31, 179-194.

2 S. Benjamin, S. Pradeep, M. S. Josh, S. Kumar and E. Masai, J. Hazard. Mater., 2015, 298, 58-72.

3 Directive 2005/84/EC of the European Parliament and of the Council of 14 December 2005, Official Journal of the European Union, 2005, L 344, 40-43.

4 See http://echa.europa.eu/candidate-list-table/-/substance/ for EHCA - European Chemicals Agency, Candidate List of Substances of Very High Concern of Authorisation.

5 H. Y. Shen, Talanta, 2005, 66, 734-739.

6 M. L. Juhasz and E. S. Marmur, Dermatol. Ther., 2014, 27, 317-322.

7 G. Sadeghi, E. Ghaderian and A. O'Connor, The Downtown Review, 2015, 1, 2.

8 D. Kashyap and T. Agarwal, Sci. Total Environ., 2018, 635, 817-827.

9 A. Paluselli, V. Fauvelle, N. Schmidt, F. Galgani, S. Net and R. Sempéré, Sci. Total Environ., 2018, 621, 578-587.

10 M. V. Russo, P. Avino, L. Perugini and I. Notardonato, RSC Adv., 2015, 5, 37023-37043. 
11 J. Fischer, K. Ventura, B. Prokeš and P. Jandera, Chromatographia, 1993, 37, 47-50.

12 C. George and H. Prest, LCGC North Am., 2002, 20, 142-151.

13 D. Smith and P. Španěl, TrAC, Trends Anal. Chem., 2011, 30, 945-959.

14 D. Smith and P. Španěl, Analyst, 2011, 136, 2009-2032.

15 W. Lindinger, A. Hansel and A. Jordan, Int. J. Mass Spectrom. Ion Processes, 1998, 173, 191-241.

16 R. N. González-Méndez, P. Watts, D. Olivenza-León, D. F. Reich, S. J. Mullock, C. A. Corlett, S. Cairns, P. Hickey, M. Brookes and C. A. Mayhew, Anal. Chem., 2016, 88, 10624-10630.

17 B. Michalczuk, L. Moravsky, P. Papp, P. Mach, M. Sabo and S. Matejcik, Phys. Chem. Chem. Phys., 2019, 21, 13679-13685.

18 T. Su and W. J. Chesnavich, J. Chem. Phys., 1982, 76, 5183-5185.

19 W. F. Kuhn, J. Chem. Phys., 1968, 49, 5550.

20 E. P. L. Hunter and S. G. Lias, J. Phys. Chem. Ref. Data, 1998, 27, 413-656.

21 ChemSpider, Diethyl phthalate, Properties, Predicted - ACD/ Labs, http:/www.chemspider.com/Chemical-Structure.13837303. html?rid=aa9741f9-550c-4b10-8ab7-478a749dba82, accessed 10/24, 2019.

22 D. Smith and P. Španěl, Mass Spectrom. Rev., 2005, 24, 661-700.

23 J. M. Thompson and D. B. Perry, J. Environ. Monit., 2009, 11, 1543-1544.

24 P. S̆panĕl and D. Smith, Rapid Commun. Mass Spectrom., 2001, 15, 563-569.

25 P. Spanel and D. Smith, Curr. Anal. Chem., 2013, 9, 525-539.

26 NIST Chemistry WebBook, NIST Standard Reference Database 69, U.S. Secretary of Commerce, National Institute of
Standards and Technology, http://webbook.nist.gov/chemis try/, cited November 2018.

27 G. Bouchoux, J. Y. Salpin and D. Leblanc, Int. J. Mass Spectrom. Ion Processes, 1996, 153, 37-48.

28 H. Fales, G. Milne and R. Nicholson, Anal. Chem., 1971, 43, 1785-1789.

29 Y. A. Jeilani, B. H. Cardelino and V. M. Ibeanusi, J. Mass Spectrom., 2010, 45, 678-685.

30 M. Lacko, P. Papp and ̌̌. Matejčík, J. Chem. Phys., 2018, 148, 214305.

31 Y. A. Jeilani, B. H. Cardelino and V. M. Ibeanusi, J. Am. Soc. Mass Spectrom, 2011, 22, 1999-2010.

32 F. W. McLaffrety and F. Tureček, Interpretation of Mass Spectra, University science books, Sausalito, 1993.

33 T. E. Daubert, Physical and thermodynamic properties of pure chemicals, Data compilation Hemisphere Pub. Corp., New York, 1989.

34 D. A. Hinckley, T. F. Bidleman, W. T. Foreman and J. R. Tuschall, J. Chem. Eng. Data, 1990, 35, 232-237.

35 United States Environmental Protection Agency, Dipropyl phthalate - Summary, https:/comptox.epa.gov/dashboard/ dsstoxdb/results?search=DTXSID5031133\#properties, cited March 2020.

36 S. F. Donovan, J. Chromatogr. A, 1996, 749, 123-129.

37 F. Cacace, G. De Petris and F. Pepi, Proc. Natl. Acad. Sci. U. S. A., 1997, 94, 3507-3512.

38 M. Lacko, F. Piel, A. Mauracher and P. Španěl, Phys. Chem. Chem. Phys., 2020, 22, 10170-10178, DOI: 10.1039/ d0cp00297f.

39 D. Smith, T. W. E. Chippendale and P. Španěl, Rapid Commun. Mass Spectrom., 2014, 28, 1917-1928. 